\title{
La Barranquilla de Voces: ejercicios de una re- cartografía espacial. ¿Cómo circuló la revista Voces vista como una materialidad? ${ }^{1}$
}

\section{The Barranquilla of Voces: Exercises of a Spatial Re- mapping. How did Circulate the Voces Journal as a materiality?}

\section{Resumen}

Socializar el estudio realizado a la Revista Voces -revista barranquillera de principios del XX que promocionaba materiales literarios- a partir de una lectura espacial y material en la que se hará uso de mapas -tipo GPS, Google maps- tanto para la reconstrucción de la Barranquilla de esa época como para develar la forma como circuló y se consumió la revista en el espacio. Lo que se busca en este trabajo de investigación es visibilizar lo geográfico traer de nuevo la geografía al debate de las ciencias sociales- visto como un elemento definitivo y concluyente en la invención literaria re-ubicando el concepto de mapa tanto como una categoría de estudio y análisis como un instrumento de observación e investigación para el desarrollo de un corpus histórico y literario. Este nuevo viraje que propongo con el uso de diversas plataformas busca poner de manifiesto la relación discursiva que hay entre los modos en que se sitúan los personajes -la génesis de unos productores e instituciones actuantes que operaron en lo urbano, así como las prácticas involucradas en la elaboración, edición , fabricación y circulación de la revista Voces en el espacio barranquillero- y las correspondencias entre las estructuras sociales de la Barranquilla de aquella época -campos económicos, culturales, políticos y, sobre todo urbanos- con las estructuras y "motivaciones" internas del "sistema" literario de Voces.

Palabras claves Revista Voces; Barranquilla; "Sistema" literario; Espacialidad; Prácticas culturales.

1 En el siguiente enlace se puede revisar cómo circuló la revista Voces reconstruida desde Google Maps: https://drive.google.com/open?id=1JP7QI3CZXzBqEzc0p1lv8VFSjEI\&usp=sharing 


\begin{abstract}
To socialize the study made to the Voces Magazine - Barranquillera magazine of the early 20th century that promoted literary materials - from a space and material reading in which maps will be used - GPS type, Google maps - both for the reconstruction of Barranquilla of that time as to unveil the way the magazine circulated in and out of space. What is sought in this research work is to make the geography visible - to bring geography back to the debate of the social sciences - seen as a definitive and conclusive element in literary invention relocating the concept of map as much as a category of study and analysis as an instrument of observation and research for the development of a historical and literary corpus. This new turn that I propose with the use of digital platforms aims to reveal the discursive relationship that exists between the way the characters are situated - the genesis of producers and acting institutions that operated in and from the urban as well as the practices involved in The elaboration, edition, manufacture and circulation of the magazine in Barranquilla space, as well as of the spatial correspondences between the social structures of the Barranquilla of that time-economic, cultural, political, and especially urbanfields with the structures and motivations "Internal to the Voices literary" system.
\end{abstract}

Keywords Voices Journal; Literary “Systems"; Spaciality; Cultural Practices.

La Revista Voces, fue una publicación que circuló desde 1917 a 1920 en la ciudad Barranquilla -Colombia-, y ha sido catalogada por algunos críticos de reconocida prestancia internacional, como Ángel Rama y Jacques Gilard, como un punto de referencia obligado cuando se quiere hablar tanto del proceso literario en Colombia -su devenir- como de los campos de producción cultural que estuvieron vinculados con la promoción y divulgación de materiales literarios. El valor simbólico/cultural de Voces es invaluable, ya que como campo cultural se adelantó a otras revistas literarias tan importantes en Latinoamérica como Proa y Martin Fierro, en Buenos Aires, Revista Avance, en la Habana, Contemporáneos, en México o Amauta, en el Perú, alzándose cómo una completa novedad dentro del panorama colombiano y americano. Tanto que para las primeras décadas del veinte en el universo de las letras colombianas no hay nada parecido a la labor editorial que cumplió la revista, ni Universitas, en Bogotá, ni Panida, en Medellín, alcanzaron la dimensión literaria de esta, pero aun así su desconocimiento sigue siendo tan grande como su aporte a las letras nacionales.

La labor editorial realizada por la Revista Voces fue sorprendente en sus tres años de existencia ya que como campo de producción cultural logró mantener sus propias leyes de funcionamiento y operación a pesar de las fuertes transformaciones y tensiones histórico culturales que padeció Barranquilla a principios del XX -transformaciones en términos urbanos, industriales, económicos y culturales-. Por ello, su práctica dentro del campo cultural debe ser vista como un auténtico desafío no solo dentro de los órdenes literarios nacionales e internacionales con su marcada agenda integracionista y su apuesta por otros eslabones discursivos culturales no dominantes, sino porque, dentro de los campos barranquilleros ligados a la divulgación de la literatura y la cultura, se constituyó así misma como una actividad autónoma y marginal gracias a un 
modelo de producción diferencial y diferenciado que sostuvo en sus sesenta ediciones. pero ¿cómo una revista editada en Barranquilla se sitúa a la vanguardia de todas las publicaciones de su género en el continente?

\section{La Barranquilla de Voces: ejercicios de una re-cartografía espacial (1917- 1920) $)^{2}$}

La historiografía local ha ahondado continuamente en la serie de cambios y transformaciones que experimentó Barranquilla a finales del siglo XIX $^{3}$ y principios del XX . Debido a esto, la mayoría de los estudios parten de la idea de que Barranquilla era "La puerta de oro de Colombia", el primer puerto marítimo y fluvial del país, en donde estuvo la primera emisora de Colombia, el primer teléfono, el acueducto "más moderno", la primera compañía de aviación comercial de América Latina y, sobre todo, donde se forjó la primera urbanización moderna: el barrio El Prado, eje de la mayoría de los estudios urbanos sobre la ciudad que se han efectuado. Pero ¿Qué eventos relacionados con la actitud que asumió la ciudad hacia el espacio urbano ajustó y adecuó la forma de fabricación, edición y circulación de la revista de Vinyes? ${ }^{4}$

Para poder empezar hablar de aquella Barranquilla -y más exactamente del lugar en donde se fabricó, circuló y se consumió la revista- es necesario hablar del área urbana que la vio crecer $^{5}$ ya que ese espacio a principios del veinte se

${ }^{2}$ Este estudio de Voces visto desde sus mediaciones y condiciones socio-históricas, pretende desmitificar la relación mágica establecida por la historiografía literaria tradicional entre el escritor y la obra, para situarla -y pensarla- desde otros bordes discursivos y con otros actores que están implicados en la producción de la obra literaria y hacen parte activa del el "sistema" de relaciones.

${ }^{3}$ Hay que entender que el desarrollo urbano de Barranquilla a principios del XX estuvo directamente influenciado por el rápido crecimiento urbano de la ciudad -como lo devela la urbanización del barrio El Prado- como de las constantes ampliaciones que se hicieron en la intendencia fluvial de la "arenosa", gracias a la consolidación progresiva de Barranquilla como puerto -obras como el Ferrocarril de Bolívar (1871), construcción del Muelle de Puerto Colombia, la fundación del poblado de Puerto Colombia y la edificación tanto de los edificios para la estación del tren como el de la Aduana, lo que devela el sentido espacializado que tuvo la modernidad como discurso en la Barranquilla de finales del diecinueve y principios del veinte(Madachi)

4 Lo que se intenta develar es cómo la estructura de la revista -su toma de posición y decisión, sus oposiciones, sus luchas internas, sus agentes e instituciones etc.- está relacionados en gran medida con ciertos cambios y fuerzas externas a su campo de producción cultural como fue lo urbano, lo económico, lo social, lo portuario, lo político en aquella Barranquilla. Además, porque una parte de su "éxito"-en términos del alcance y la circulación de la revista- se debió, en gran medida, a ciertas decisiones que se tomaron desde principios del veinte en el espacio barranquillero.

${ }^{5}$ Uno de los muchos interrogantes que ha generado esta revista dentro de los círculos de investigación literaria sobre Barranquilla y el Caribe colombiano -y más exactamente lo que corresponde a su génesis- "¿Era -qué si- Voces -fue- el resultado de un proceso cultural real?" (Illán Bacca). Una Pregunta que ha definido gran parte de las investigaciones que se han 
erigió como el mayor centro de crecimiento urbano y cultural de la costa Caribe colombiana. Un espacio urbano formado por cuatro vértices que fueron urbanamente trazados de arriba y abajo por el paso del tranvía público. Cuatro puntos de intersección que tenían como su centro máximo la famosa Iglesia de San Nicolás en donde la figura política -y también literaria- del Padre María Revollo ofrecía diariamente el servicio ceremonial cristiano. Este cuadrilátero siendo el más populoso y bullicioso y agitado de Barranquilla (Madachi), fue el sitio de reunión, asentamiento y movimiento de las jóvenes promesas del periodismo y las letras barranquilleras. Además de funcionar como una plaza y punto de referencia para el movimiento comercial y portuario de la región 6 (Madachi), se transformó en un fenómeno espacial autónomo en donde diversas figuras culturales discutían sobre diversos temas como literatura, cultura, poesía, así como lo que se publicaba en las revistas y periódicos de la época. Se debe entender que esos espacios delimitados se convirtieron en los puntos de asentamiento en donde se agruparon los jóvenes que iban a ser llamados a ocupar las posiciones dentro del campo de la producción cultural vinculados con la escritura en Barranquilla. Un perímetro urbano que fue entendido como un área abierta a la transformación, a la alteración, al movimiento mismo y que se configurará como la representación de la revuelta y del empuje que asumieron algunas experiencias editoriales"

realizado acerca de la revista de Vinyes - académicos como Jacques Girald, Jordi Llano, Ramón Illán Bacca, Germán Vargas, Ernesto Volkening, Gilberto Loaiza Cano, Álvaro Medina, entre otros.- Problemática que ha sido también expuesta por el crítico uruguayo Ángel Rama tanto en su estudio crítico que realizó de la obra literaria de Gabriel García Márquez como en su estudio crítico de la novela latinoamericana en el siglo veinte "[...] Esa palabra "nuevo" es la que con mayor frecuencia escribe uno de los personajes mitológicos de la literatura latinoamericana, ese Ramón Vinyes que a partir de 1917 da a conocer en una revista provinciana -haciendo referencia a la revista Voces que para la fecha era un zona oscura dentro de las actividades literarias continentales- las audacias de Dormée y Reverdy, el Traité du Narcisse de André Gide [...]" (Rama 48). Lo que demuestra, a fin de cuentas, que si bien algunos críticos se han ocupado del estudio, análisis y teorización de Voces -y por extensión de Vinyes y de otras plumas que participaron activamente en la revista barranquillera-, el desconocimiento sobre lo que esta representó sigue siendo muy grande.

${ }^{6}$ Dentro de ese espacio urbano, Barranquilla, se forjo $-\mathrm{y}$ se entendió- como un ámbito de modernización, ya que esos vértices, encumbrados por la plaza San Nicolás, tuvieron la oportunidad de contener una dinámica vida urbana de intensidad y variedad notoria con una vida pública de altísima significación -como fueron las incontables empresas editoriales-.

${ }^{7}$ Julio H. Palacio quién fuera colaborador asiduo de la revista Voces -tenía una separata dentro de la revista y, además, hizo parte del cuerpo editorial y, por ende, de su toma de decisiones - en sus diarios habla de aquella revolución editorial y que estaba cifrada tanto en esos vórtices urbanos como en la multiplicidad de periódicos que " [...] la prensa de Barranquilla en 1909 estaba representada muy decorosamente y servida con inteligencia por "El Conservador", dirigido por don Enrique Rach Silva, padre del gran poeta Miguel Rach Isla, por "Rigoleto", el diario que fundáramos en 1902 Eduardo Ortega y yo, a cargo entonces del hermano del primero, Daniel Ortega, y de Luis Carlos Paéz, quien, a la sazón, desempeña también el puesto de secretario del Banco Comercial de Barranquilla. Y por último, "El Comercio", dirigido por Gabriel H. Pineda, en quien había de reconocerse cierto instinto para el periodismo, cierta "sansfacon" -entre otros 


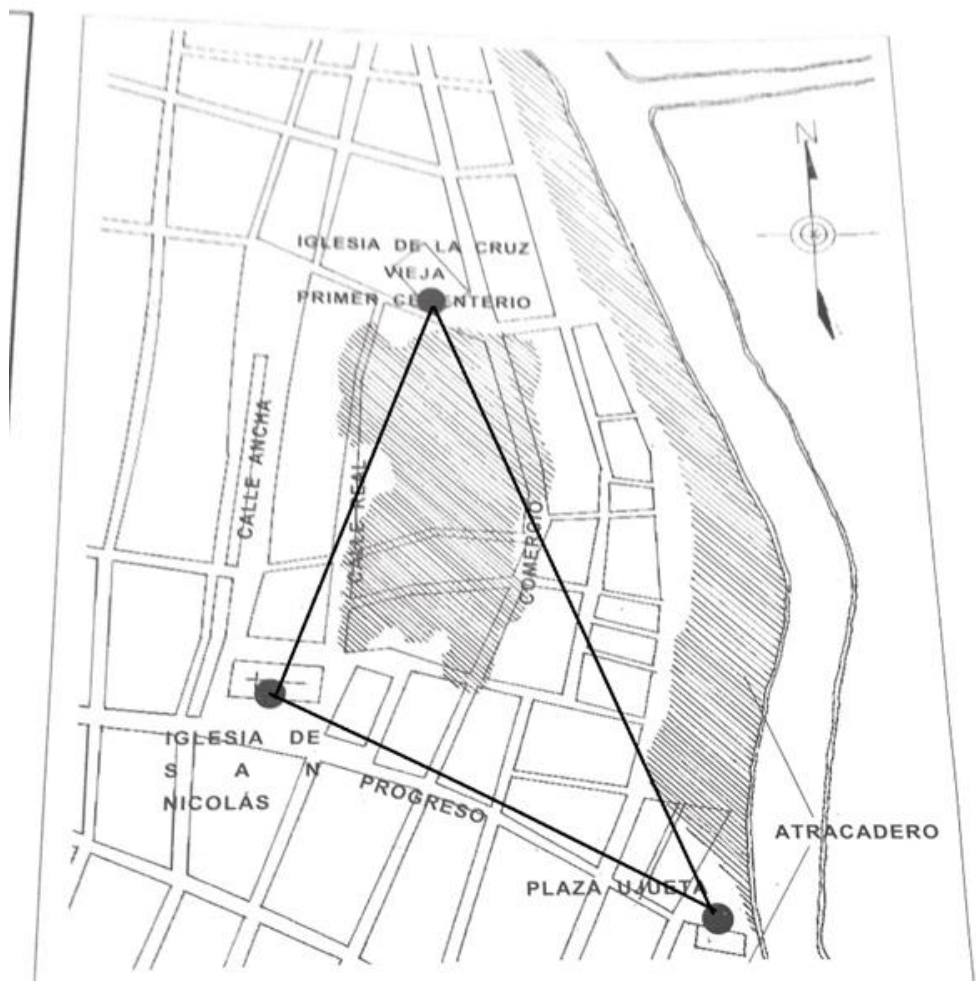

llustración 1- Cuadro $A^{8}$. (Montoya Márquez)

periódicos- [...]" (Palacio 197). Despertar editorial que también aparece en las crónicas escritas por Miguel Goenaga llamadas Lecturas locales -fundador del periódico "El Siglo"-

${ }^{8}$ Se traza el denominado "cuadrilátero" del Atlántico, compuesto por las calles del Comercio, Calles del Progreso y la Calle Real que operaban a principios del XX como ejes de la actividad comercial y financiera -gran parte de las empresas editoriales de la época quedaban en aquel sector y la de Voces no fue la excepción-. La plaza San Nicolás, la calle de Comercio eran un área urbana se de varios bancos -como el antiguo Banco Dugand- y los principales almacenes-, la calle del progreso -similar a la del Comercio- y la calle Real -de carácter administrativo, también se le llamó la calle de los Juzgados-. 


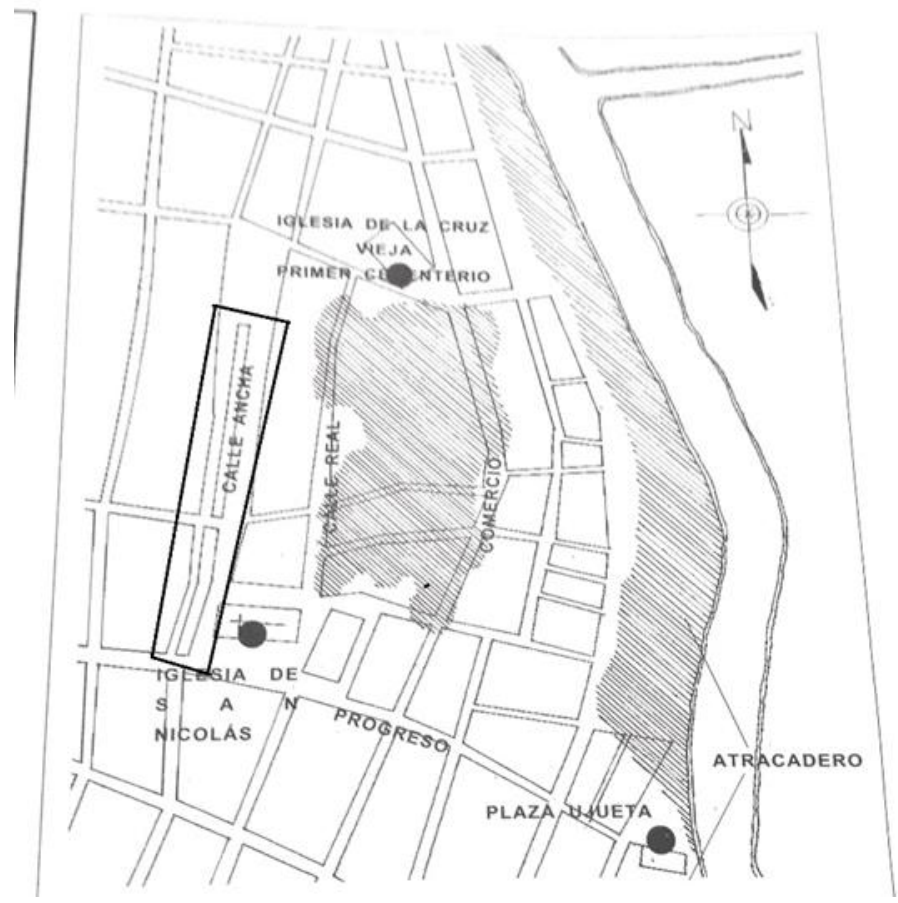

Ilustración 2. Cuaro B9. (Montoya Márquez)

El proceso de sistematización de Voces, es decir, su configuración interna como también los grados de dependencia o independencia que gozó frente a otros campos externos a su producción se vio reforzado gracias la consolidación de aquel triángulo urbano. La simplicidad de Voces -pensada en términos de circulación y consumo de la revista- fue el resultado de la búsqueda de una eficiencia funcional que estuvo vinculada con las experiencias urbanas y con la alta heterogeneidad socioeconómica y la gran diversidad cultural que palpitaba en aquella ciudad.

En el Cuadro A vemos al Callejón del progreso - que unía el atracadero y la iglesia San Nicolás-, la calle del comercio -entre Progreso y la Cruz Vieja- y la calle Real -entre la Cruz Vieja y San Nicolás-. En el Cuadro B vemos el famoso

9 La calle Ancha - o como algunos lo conocían como el Camellón Abello- fue un boulevard que operó a principios del XX como el gran centro de actividades culturales y literarias que tenía como punto de referencia la plaza San Nicolás - gran parte del consumo indirecto de la revista Voces se realizó en esa zona de Barranquilla-. 
Camellón Abello ${ }^{10}$. Tanto uno como otro, fueron en las primeras décadas del veinte, centros urbanos definitivos -de necesaria referencia cultural e histórica ${ }^{11}$ y que codificaron y permitieron la articulación del campo de producción de Voces. Se debe entender, que la toponimia, ubicación y disposición de estas en la "arenosa" es indicadora del carácter funcional por las que fueron imaginadas. Estos espacios -las calles y las plazas- se concibieron mirando más allá del mar, exactamente en aquellos lugares de donde provenían sus usuarios -y de dónde provenía el movimiento- pero no solo para lograr vínculos comerciales y atraer, con ello, capitales y tecnología modernizadora, y con ello, eventualmente, expresiones de modernismo a la ciudad, sino que buscaban concebir un espacio que tuviera la oportunidad tanto de contener una dinámica vida urbana en intensidad y variedad con prácticas históricas definidas y con modos de operaciones culturales diferenciadas como terminó siendo la experiencia editorial de Voces. La interacción, pensada siempre en términos de relación/tensión de la revista con las instituciones y espacios involucrados -clubes, bibliotecas, centro de fabricación, teatros, calles, lugares de asentamiento como las plazas públicas, etc.- implica, como primera medida, el reconocimiento de la estructura urbana y de la relación que hay entre estos con Voces. Tanto el Cuadro A como el Cuadro B comparten un código común que es el modo cómo se pretendió ocupar el espacio urbano y, por ende, el significado que se buscó para esa Barranquilla. La primera lectura denota un código funcional: tanto el A como el B sugieren que el espacio público en Barranquilla fue definido desde un principio motor -una suerte de ciudad lineal- que codificó un espacio para el movimiento y un espacio para el asentamiento, lugares en el que necesariamente convergieron agentes e instituciones internos como externos a la revista y que serían expresados espacialmente en la plaza San Nicolás y del Camellón Abello. La presencia tanto de uno como otro, formando un todo espacial con el principal espacio público, en términos de la activación y dinamización de la revista Voces, es que los dos puntos -vista esa Barranquilla como una ciudad lineal - fueron las estructuras que se encargaron de cohesionarla y articularla. El Camellón Abello y la plaza San Nicolás son espacios que integraron la ciudad emergente; en ellos no solo se

${ }^{10}$ Es un espacio que debió definirse en los primeros años del siglo XX al mismo tiempo que el cuadrilátero de Barranquilla (Chamorro González). Este sitio es un espacio bastante particular en la historia de la ciudad por motivo de las constantes referencias literarias y gráficas que tiene. Además, era el centro que aglutinó a la élite intelectual de la ciudad. Ramón Vinyes, Héctor Parias y Gómez de Castro, Enrique Restrepo, todos ellos colaboradores y editores de Voces, frecuentaban este sector de la ciudad.

${ }^{11}$ La importancia tanto de la calle Ancha -el Camellón Abello- como del cuadrilátero es tal en el crecimiento económico y cultural de la "arenosa" que fueron los primeros lugares con iluminación eléctrica en la ciudad como consecuencia de la población flotante que circulaba por sus calles y avenidas. Este signo del carácter urbano y moderno en Barranquilla -ligado a la instalación de luz eléctrica que traería nuevas prácticas de operar en la ciudad, nuevos usos de lo urbano como nuevos operadores- permite imaginar unos espacios urbanos ligados a una creciente actividad de cultural y económica. Espacios que dieron vida a grandes empresas editoriales como fue la de Ramón Vinyes. (Caballero Leguizamón). 
aprecia el cambio económico y social, sino que fueron el primer punto de localización e interacción de aquellas nuevas prácticas culturales, y en donde se van a establecer, además, todo tipo de consumos culturales. Todo este proceso de consolidación urbana que estuvo ligada al proceso de iluminación y electrificación de estos espacios urbanos a principios del XX, consolidó, primero, los campos de poder más prioritarios como fueron aquellos espacios vinculados a la esfera de lo económico y político como ocurrió con las calles del Comercio, del Progreso y la calle Real, los grandes ejes de la actividad comercial y financiera de Barranquilla. Y segundo, aparecieron los campos de poder secundarios que eran los encargados de la producción cultural como pasó en la antigua calle Ancha que fue el espacio indicado para las actividades culturales y recreativas (Chamorro González). Como consecuencia de esto, en esos espacios se comenzaron a localizar los lugares de lectura, compra y esparcimiento de las empresas escriturales. Es más, el carácter de estos lugares articulados dentro de un eje central como la plaza, se transforma en un indicador para comprender la forma como circuló la revista Voces en Barranquilla, siendo ese el espacio indicado para el intercambio comercial, la actividad de las tertulias y el consumo indirecto o directo de la revista Voces.

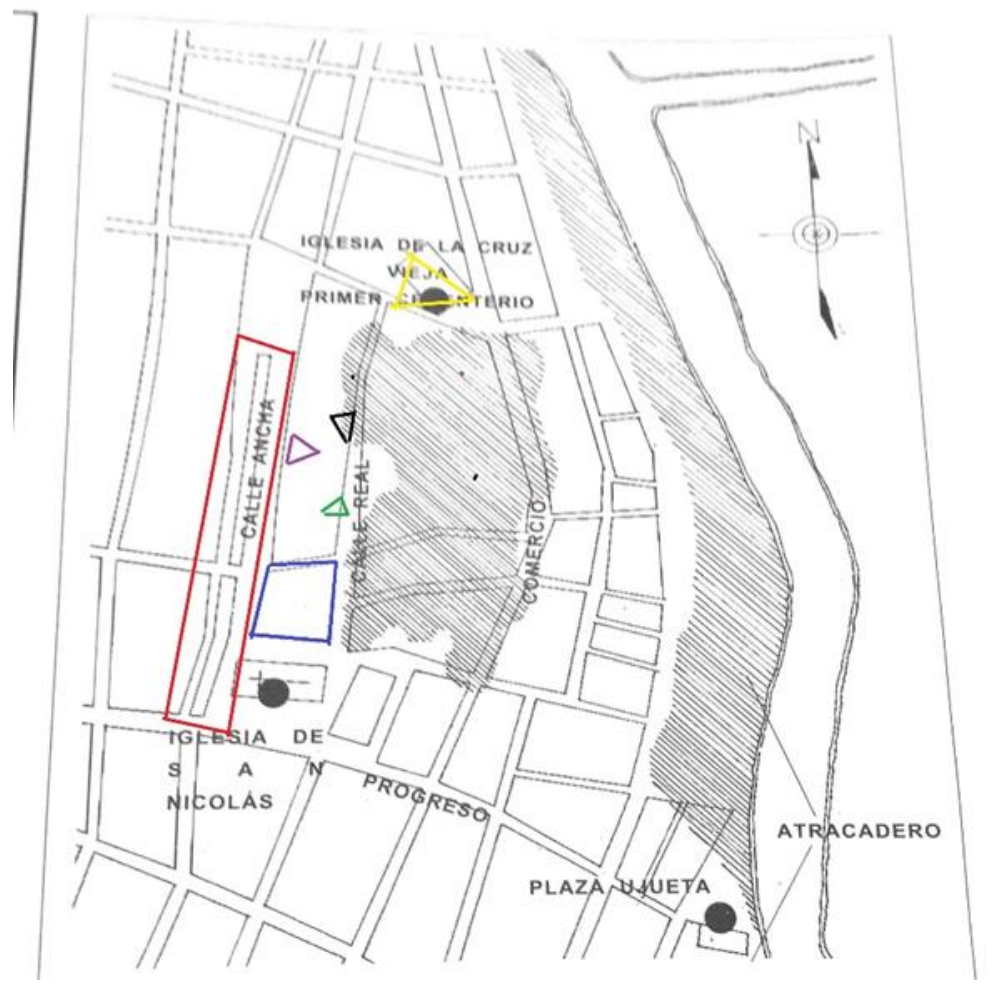

Ilustración 3. Cuadro $C^{12}$ (Montoya Marquez)

12 De rojo, tenemos la calle Ancha -o el Camellón Abello o Paseo Bolívar- como el espacio en donde se llevaban a cabo las actividades culturales y las tertulias -lugar en donde se generó el 
Visto así, la dimensión territorial y urbana de esos dos núcleos que convergían bajo la mirada de la iglesia de San Nicolás, entendiendo esta como un entre medio de los dos núcleos que activaron y articularon al campo de producción de Voces, ya que su plaza fue utilizada, a principios del veinte, como un ágora pública, que unía a cada lado de su cuadrilátero -completamente arborizado cubierta por la sombra de gigantes arboles de caucho - los dos puntos de crecimiento comercial y cultural de la ciudad. Este lugar será leído como un punto de confluencia - pero también de tensión- no solo de las actividades que tuvo en ella la revista de Vinyes sino también el espacio en donde se manifestaron las tensiones entre agentes e instituciones de diversos campos de poder. La cercanía y linealidad de estos hizo posible, en términos urbanos, la dinamización y activación de diversas actividades socio-culturales bajo un número limitado de agentes e instituciones -consumidores, productores y distribuidores- que operaron alrededor de la revista y que, además, trabajan y vivían a lo largo y ancho de esas calles. Operaciones culturales que se generaron a partir del encuentro de diversos campos en un reducido espacio urbano permitiendo el posicionamiento de áreas especializadas tanto para el encuentro como para el movimiento pero no solo de transeúntes, forasteros e individuos que aparecían y deambulaban de arriba abajo por sus calles, sino, para un sinfín de operaciones culturales, sociales, artísticas, etc. que convergieron en ellas, actividades que permitieron en corto plazo, la activación y dinamización de una "verdadera" marcha cultural e editorial en la ciudad -revoluciones culturales que se llevaban a cabo en los sitios aledaños al perímetro de la plaza San Nicolás en algunas instituciones ${ }^{13}$ vinculadas al campo de la producción cultural como lo fue el Club de Barranquilla o los teatros

consumo indirecto de las publicaciones de Voces-. De azul, la plaza de San Nicolás como punto de confluencia entre dos puntos de desarrollo urbano y movimiento del "sistema" literario de Voces. De verde, está señalizada donde estaban ubicadas en el primer año -desde el 10 de agosto de 1917 hasta el 10 de febrero de 1918- las instalaciones en donde se editó -y se fabricó- la revista del catalán Vinyes, Hipólito Pereyra y Gómez de Castro sobre la Calle Real número 37 una calle en donde estaban ubicadas también los edificios administrativos y jurídicos de Barranquilla-. La oficina de Voces después será movilizada a la calle Santander con la carrera del Progreso -Calle 18 carrera 14- el 20 de febrero de 1918 y allí estará hasta su última publicación-. En amarillo, inicialmente la Calle de La Cruz vieja, por haber estado ubicada sobre ella la primera iglesia de Barranquilla, al Construirse la Iglesia de San Nicolás, la Vieja Iglesia fue demolida y más tarde en este sitio fue construido en 1894 el Teatro Emiliano. De morado, está el Club de Barranquilla sobre el Paseo Bolívar o Camellón Abello. De negro, fue el lugar donde funcionó el Teatro Cisneros, construido por el general Diego A. de Castro en el lugar donde había funcionado desde 1876 el Salón Fraternidad e inaugurado el 19 de abril de 1914.

13 En este trabajo la palabra instituciones se entenderá como un agregado de diversos factores implicados en el mantenimiento de la literatura como actividad socio-cultural (bibliotecas, centros de lectura, librerías, cafetines, etc.). Además, es la encargada de legimitizar-sancionado o rechazando- ciertas prácticas culturales sobre otras. (I. Even-Zohar) 
Cisneros y Municipal ${ }^{14}$-. Y porque esos espacios construidos y pensados como colectivos, gracias a la estrecha vinculación que tuvieron con las experiencias portuarias y económicas de la ciudad, se transformaron en espacios urbanos y públicos que codificaron las actividades editoriales que allí emergían -prácticas editoriales y escriturarias que intentaron emular aquellos registros que venían de otras latitudes-.

El campo de producción de Voces no puede ser comprendido ni analizado sino se tiene en cuenta a esa Barranquilla como un espacio dispuesto a ciertas

${ }^{14}$ En Barranquilla -en el primer segundo decenio del siglo veinte- predominaba cierto culto a las letras y a ciertas prácticas escriturales que estaban vinculadas a la actividad periodística, aspecto que no reñía con el brillante refinamiento y con las eficaces labores comerciales que se realizaban en aquella época en la "arenosa", es más, tanto uno como otro se complementaban. Este aspecto resulta definitivo para saber cómo se dieron las luchas entre campos de poder, es decir, la relación/tensión que existió entre el "sistema" de Voces con otros campos y fuerzas externas que eran dominantes a la de producción cultural y que eran de índole económico y político en la ciudad. Dentro de estas relaciones de fuerza entre agentes e instituciones de uno y otro campo el Club de Barranquilla tuvo una labor fundamental. En la noche de 1914, el club, eje cultural del cuadrilátero barranquillero, se vistió de fiesta, la comparsa Black And White solo fue el aperitivo en una noche en que "los amplios salones del club, ofrecían un majestuoso esplendor... el salón tenía un aspecto de rara deslumbración maravillosa. Las bombillas eléctricas fingían una nube de luciérnaga, derramando sobre la majestuosidad de la sala el brillo luminoso de su luz" (Goenaga 260) Esa noche se vería pasar no solo el gran desfile de las damas de Barranquilla en vísperas del Carnaval de Barranquilla promocionando la belleza del Caribe en ébanos colores sino que también, fue el desfile de la representación de la labor periodística y el ejercicio cultural de las letras en muchos años en la ciudad. Hermosos cuerpos tallados por el inclemente sol ribereño y por el salubre viento del Caribe desfilaron aquella noche, llevando a la par de su belleza la labor periodística de la "arenosa". Esta procesión llevada a cabo en el Club Barranquilla muestra la vitalidad que tenían, para aquella época, las empresas editoriales en Barranquilla develando que el ejercicio del periodismo en el Caribe $-\mathrm{y}$ sobre todo en la "arenosa"- fue muy ejercitado y diverso y, que, además, estaba altamente vinculado a los espacios culturales y urbanos que fueron surgiendo en la "arenosa". Estas fiestas que se celebraban a lo largo y ancho del boulevard y del cuadrilátero ponen en evidencia que el ejercicio del periodismo y de las letras no era una práctica que fuera mal vista a causa del prominente desarrollo comercial y empresarial de la ciudad como algunos académicos y estudiosos pretenden soslayar -aunque sí es cierto que algunas de esas prácticas discursivas y editoriales estuvieron subordinadas a ciertos principios de jerarquización externa -muchos periódicos de la arenosa tenían dentro de sus páginas textos referentes a campos económicos y políticos como lo fue "El Nuevo Siglo", "El Promotor", "El Rigoletto", etc.-. La práctica escrituraria, primero, en cuanto a su producción era altísima y lo demuestran los múltiples periódicos que aparecieron desde de 1871 en Barranquilla, y segundo, porque el empresariado, esa nueva mentalidad que surgió a causa de las migraciones jalonó esas experiencias escriturales en la ciudad. Se debe dejar claro, que las acusaciones de que no se leía en Barranquilla y tampoco se escribía aparecen, primero, por el desconocimiento de la tensión evidente de unos campos de poder en Barranquilla y las oportunidades que ofrecía la cuidad para todo tipo de empresas -como fueron las escritas, - y segundo, por descontextualizar la práctica al compararla con la vida editorial de Bogotá. Se debe dejar claro, que la credibilidad de esas empresas editoriales que surgieron en Barranquilla es bastante cuestionada debido a que la gran mayoría de esos periódicos y revistas, en aquella época, rivalizaban entre sí -como se puede ver en las editoriales del periódico El Estandarte - ya que en sus proyectos editoriales defendía todo tipo de posturas, ya sean de carácter político, ideológicas, comercial- con el ejercicio realizado por Voces. 
prácticas y usos que impuso la modernidad como discurso. Los contenidos atípicos que fueron publicados en la revista de Vinyes como, también las decisiones editoriales que la promovieron en sus tres años de existencia aparecen como marcas de aquellos registros culturales que venían en aquella época de afuera y que fueron absorbidas por sus editores y colaboradores en las calles del cuadrilátero. No es gratuito, por ello, la altísima predilección por los contenidos que tuvo la revista y las tomas de decisiones al publicar un tipo de literatura completamente foránea -aunque también se publicó en sus páginas literatura local-.

El carácter público y abierto de aquellos lugares definió, en gran medida, el signo vinculante que tuvo la cultura barranquillera en aquella época. Como centros aglutinantes, cada habitante de la ciudad fuera empresario, político, comerciante, tendero, capitán, bracero, editor, tipógrafo, escritor, músico, religioso, etc. podía hablar allí sobre infinidad de temas, construyendo para así, una cultura diversa e "igualitaria" en oposición a otras zonas culturales del país. El Camellón Abello "en cuyas bancas poetas, periodistas, músicos se sentaban a hablar -horas tras horas- sobre libros, poemas, política, literatura, ciencia y filosofía". (Fondo Mixto de Promoción de la Cultura y las Artes ) es el mejor ejemplo de un proceso de construcción de un espacio incluyente y solidario en Barranquilla -aspecto fundamental que fue promulgado y propagado en la editorial de Voces- de la cultura y el conocimiento. Por ello, es necesario resaltar que el aire que se respiraba en ese entonces en la "arenosa" era muy diferente al de otras ciudades como Medellín y Bogotá ${ }^{15}$.

15 Para esa misma época en Bogotá a principios del XX, con su apretada agenda de revisionismo colonial, el café Windsor era el sitio más privilegiado para las tertulias santafereñas -es decir, tanto para el consumo directo o indirecto de artefactos literarios como las revistas que circulaban en la capital colombiana-. Este espacio era un recinto privado y exclusivo a los que asistían solo los pocos miembros de escritores que hacían parte del establishment literario de la capital. Era un lugar que se presentaba ajeno y alejado - a causa de la clausura socio-cultural que implantabade las calles y de las plazas de la ciudad, lugares en donde está, primero, la gente -el consumidor y por ende una diversificación de los tipos de consumo- y, segundo, del movimiento -cultural, social, humano, etc.-. Para aquella Bogotá del año de 1918 circuló por la capital una revista especializada en literatura llamada Revista Cultura -contemporánea a Voces - y era un extensión más del café Windsor - ese era el espacio en donde se consumía la revista- y estaba conformada por intelectuales veteranos y conservadores, cautelosos de las viejas formas y amantes del parnasianismo y que utilizaban el café para seguir repitiendo hasta el cansancio las citas de Rufino sobre la castellanización de la literatura bogotana, o de lo que escribió el crítico cultural Restrepo o para adular aún más la amarga poesía de Núñez. Es solo hasta 1919 cuando hubo una tímida eclosión de jóvenes - algo similar con Voces- que interesados y movidos por la bandera de la cultura y el progreso en la capital y que se fueron pronunciando, poco a poco, en la Sala Samper (Loaiza Cano), que era el sitio de exposiciones y conferencias de la Revista Cultura, ese famoso círculo que se llamaría después la Asamblea de Estudiantes (Loaiza Cano). Aquel acontecimiento que arroparía con fuerza a las nuevas promesas de las letras capitalinas nació -lastimosamente- más por el influjo del poeta mexicano Carlos Pellicer quién era el promotor de la Organización Hispanoamericana de Estudiantes que por impulso propio de las nuevas letras bogotanas. "Allí pronunciaron sus primeros discursos Gabriel Turbay, Camacho Carreño, Eliseo Arango, Guillermo Arango Mejía, Hernando de la Calle” (Arciniega). Esta 


\section{Voces: La revista vista como un campo de producción cultural. En miras de una lectura sistémica.}

Para analizar las propiedades generales del campo de producción que tuvo la revista Voces, es necesario realizar tres operaciones básicas ${ }^{16}$ (Bourdieu) es decir, tres lecturas que pretendan legimitizar académicamente, primero, la génesis de unos productores e instituciones actuantes ${ }^{17}$ operando desde la revista Voces, lo que implicaría, sin lugar a dudas, tener en cuenta la historicidad de estos como de las prácticas involucradas en la elaboración, edición y fabricación de la revista y segundo, establecer las correspondencia entre las estructuras sociales de la Barranquilla de aquella época -campos económicos, culturales, políticos- con las estructuras y "motivaciones" internas de Voces ${ }^{18}$.

Para iniciar, hay que dejar claro que la revista ocupó en sus tres años de existencia una posición dominada/dominante gozando de relativa autonomía frente a los campos de fuerzas externas que existían y se posicionaban como discursos dominantes en la ciudad. Su campo de poder que estuvo vinculado con la producción cultural tanto en la creación y divulgación de materiales netamente

asamblea dejó "grandes agitaciones de ideas, academias de poesía desobediente, disidencias políticas, escuelas de economía, periódicos y sociedades literarias" (Arciniega). Fue tan grande la sacudida cultural de la asamblea, que para 1919 todas aquellas fuerzas fueron canalizadas en la famosa Revista Azul, que repitiendo el nombre de la publicación modernista de Gregorio Gutiérrez Nájera, alcanzo a llegar a 5 números y en la que escribieron personajes de la talla de Rafael Maya, German Pardo García y Clemente Manuel Zabala y divulgaron, entre sus hojas, poemas de León de Greiff y de Abel Farina (Loaiza Cano). Mientras que Bogotá vivía en un ambiente aún con reminiscencias coloniales, ya en el Camellón Abello -Barranquilla -se llenaba poco a poco de lectores de Nietzsche, traductores de la obra de Kant y amantes de Apollinaire gracias a la labor de difusión que cumplió Voces y sus antecesoras culturales como The Shipping List y El Nuevo Tiempo literario. Aquí, la idea de la aventura editorial se convertirá en el Tropos más común, debido al imaginario de progreso que sufrió Barranquilla proyectándose en Voces en sus tres años de existencia con contenidos editoriales arriesgados, experimentación tipográfica en sus números, etc.

${ }^{16}$ Operaciones que Bourdieu soslaya bajo tres niveles de la realidad social que sólo pueden explicarse teniendo como referencia al campo del poder, dentro del cual nuestra revista ocupa una posición dominante.

${ }^{17}$ Hacer uso del concepto de agentes e instituciones con un marcado énfasis en su carácter disposicional pretende explicar y establecer la vinculación entre las estructuras sociales y las prácticas inmersas en el "sistema" literario de la revista.

${ }^{18}$ Esta lectura que voy a plantear a lo largo del texto permitirá que sea posible formular diferentes hipótesis acerca del cómo operan los diferentes agregados semióticos dentro de Voces -visto como una materialidad- en un contexto singular y definido. El poner en funcionamiento esta noción permitirá entender "ciertos" fenómenos literarios -no para clasificarlos ni muchos menos registrarlos-, sino con el fin de detectar ciertas leyes - modos y operaciones- que no habían sido vistos o estudiados y que rigieron y definieron lo que comprendemos como el proceso de total de Voces -edición, fabricación, producción y consumo-. Vista así, la lectura de Voces en clave de "sistema" llevaría no solo a explicar correctamente fenómenos conocidos, sino que también develaría -sacaría a luz- otros completamente "desconocidos" (I. Even-Zohar 19) que jamás se habían pensado o estudiado en relación con la literatura. 
literarios ${ }^{19}$ operó con ciertos márgenes de libertad editorial desde su nacimiento el 10 de agosto de 1917 a pesar de las irreparables paras y frenos editoriales que padeció $^{20}$. Pero ¿cómo entender esa relación dominada/dominante en Voces con otros campos de fuerzas? ¿Cómo pudo gozar de una relativa autonomía cuando el marco de acción y operación de la escritura y la prensa en Barranquilla ocupaba una posición dominada con relación a otras fuerzas más imperativas ${ }^{21}$ ? Para ello, hay que plantearse no como Voces llegó a ser lo que fue -como suelen hacer algunos de los estudios realizados a la revista-, sino más bien, cómo, dadas su procedencia cultural y las propiedades humanas, políticas, literarias, expresivas, etc. de las que fue tributario la revista pudo ocupar y producir en aquella Barranquilla fenicia un estado editorial auto-determinante frente a otras campos y dar así, una expresión más o menos completa y coherente de lo que fue su proyecto editorial.

$\mathrm{Su}$ autenticidad estuvo en presentarse como una ruptura, en primera medida, con los periódicos y revistas tradicionales que eran de dos tipos, unos que respondían netamente a los órdenes comerciales, económicos y (o) políticos ccomo The Shipping List- y, dos, los que operaban con un marco de decisiones mixtas -como el Rigoletto y El Promotor- que maniobraban entre dos lógicas, una dominante -el económico y político- y otro más residual -lo cultural y más exactamente lo que correspondía a la difusión y promoción de materiales literarios-. Y en segunda medida, con las tradiciones artísticas vigentes lo que permitió una suerte de revista con un contenido editorial de materiales que jamás habían sido leído en su propia lengua ${ }^{22}$. Estas dos rupturas resultarán definitivas no solo porque es allí donde encuentra Voces su criterio de especificidad en el

${ }^{19}$ Es necesario, explicar, siguiendo la tesis de Bourdieu, que los campos literarios como lo es Voces tienen un grado de codificación muy débil debido a que sus fronteras y sus fuerzas internas están siempre en extrema permeabilidad, es decir -como lo veremos más adelante con Voces- aglutinan y encierran un sin número de instituciones que le son ajenas - de nacimiento- a su campo de producción. (Campos del poder)

${ }^{20}$ No evaluaremos el éxito o no de la revista Voces teniendo como medida su número de ediciones decenales como tampoco por el consumo directo que tuvo en la "arenosa", sino por el progresivo -fueron tres años de consolidación editorial- proceso de autonomización de la revista frente a otros campos de poder.

${ }^{21}$ La creciente actividad portuaria y el desarrollo monetario y financiero en la Barranquilla de inicios del siglo XX hizo que se avizoraran en el horizonte social nuevos órdenes y lógicas imperantes. La cuidad se construyó bajo una jerarquización externa muy exacta y que estuvo atada a ciertos capitales vinculados con el crecimiento y la apertura de económica y el desarrollo industrial acelerado. Bajo este panorama, los otros campos de producción que no estaban estrechamente vinculados - por lo menos en sus orígenes- con esos nuevos órdenes que se erguían como dominantes, comenzaron a ocupar, dentro de sus marcos de acción, una posición dominada como ocurrió con los campos producción cultural ligados a la práctica y promoción escrituraria.

${ }^{22}$ Lo más importante de los cambios observados en Voces dentro de su política editorial es el desplazamiento que tuvo de posiciones dominantes - lo comercial, financiero, económico o político- a menos dominantes - lo literario, lo cultural- en búsqueda de una innovación en términos de proyectos editoriales. (Bourdieu) 
reparto cultural barranquillero y nacional como una revista especializada con sus propias divisiones y sus propias geografías internas, sino que desde ahí se institucionaliza un espacio en lo literario ${ }^{23}$.

Voces definió y delimitó su distancia a partir de criterios estéticos y políticos con respecto a sus similares lo que le proporcionó un código específico de comportamiento y de expresión singulares dándole a su actuar espacios alternos y variados para su agenda editorial. En su edición inaugural fechada el 20 de agosto de 1917, en el apartado denominado como Notas se establece un "norte" editorial en cuanto a que solo dialogará con estructuras estéticas, dejando al lado las ideologías o pensamientos políticos que eran los discursos dominantes dentro de los campos editoriales en la "arenosa":

Solo esfuerzo en pro de la cultura local, de espíritus preocupados, fue origen y como todo generoso alarde orientado a ese fin, aspira a colocarse fuera de las pasiones politiqueras y los pequeños prejuicios parroquiales [...] deliberadamente "Voces" no hace constar entre sus propósitos el de atarse a determinada corriente política y será su mayor empeño permanecer alejada de todas las que quitan la vida actual del país. (Voces 4 )

Ese proceder se transformó en un espacio de maniobra, en una táctica frente a un conjunto de imposiciones y estrategias que eran en esa época las precondiciones para todo proyecto editorial que surgía en Barranquilla. Su ley fundamental fue, entonces, la independencia respecto a las demandas externas formando un campo con alta independencia ${ }^{24}$ con sus propias fronteras, con sus propios capitales y sus propias vías de comunicación -aunque muchas de ellas fueron agentes e instituciones que estaban ligadas de nacimiento a otros campos de poder-. Pero ¿Cuál fue exactamente ese código específico que la convirtió en una práctica editorial diferenciada y diferenciadora con sus similares?

Para ello, habrá que analizar, dentro de esa lógica, la relación que hubo entre los agentes inmersos en la primera instancia del circuito, es decir, usando los

${ }^{23}$ En el texto La República Mundial de las letras de Pascale Casanova, el autor propone que los espacios - o el espacio- literario cuando es capaz de generar un proceso de autonomía frente a otras fuerzas externas a él -nacionales, políticas, económicas- pueden producir sus propios marcos de acción, sus propios modos de funcionamiento estableciendo así, flujos y jerarquías internas (Casanova). Este concepto de espacio literario de Casanova está en tensión con el propuesto por Bourdieu (Bourdieu) porque para el académico campos literarios tiene un grado de codificación muy débil, es decir, sus fronteras, sus capitales, y sus vías de comunicación siempre estarán en extrema permeabilidad cono otros campos no literarios a pesar de gozar con autonomía y libertad.

${ }^{24}$ Para Bourdieu (Bourdieu) los campos de producción cultural no gozan de una independencia total frente a otros espacios más dominantes a causa de la constante permeabilidad y baja codificación de sus redes y relaciones. Para Casanova (Casanova) el campo literario si tiene una relativa independencia frente a otros espacios como el económico. Y Roger Chartier (Chartier) considera a los campos de la edición y la literatura como campos autónomos cuando su actividad, práctica y operación esta liberada del discurso comercial. 
términos de Even-Zohar, a los productores ${ }^{25}$-escritores y editores de la revistay su participación en todo un conjunto de actividades que no se limitó a la mera producción escrita y su organización de estos dentro de la revista -sus tomas de posición, sus formas individuales de operación, sus gustos literarios, etc.-

Se podría afirmar que Voces contó dentro sus tres años de existencia con dos caras por medio de las cuales justificaron su proyecto editorial, caras que irían desde la edición número uno hasta la sesenta. Una más amable, conciliadora y moderada, suficientemente tradicional en sus contenidos con un alta inclinación por la literatura modernista y de fin de siglo, en donde marca la pauta un alto contenido de poesía idílica, bucólica; y otra mucho más agresiva, militante llegando casi a rayar en la ironía ${ }^{26}$ en donde solo se pretendía, primero, entablar un diálogo abierto con las novedosas estructuras poéticas que llegaban a la librería de Vinyes y que eran traducidas y publicadas por Voces y, segundo, transformar la revista en una plataforma cultural para circulación de nuevos materiales literarios.

\begin{tabular}{|l|r|r|}
\multicolumn{1}{c}{} & \multicolumn{1}{c}{ Materiales publicados } & Porcentaje \% \\
\hline Literatura Local & 126 & $54.07 \%$ \\
\hline Literatura Global & 107 & $45.92 \%$ \\
\hline
\end{tabular}

Ilustración 4. Información recopilada por el autor para este artículo.

Esas dos disposiciones editoriales que a simple vista parecen absolutamente contradictorias en términos de una empresa literaria unificada, fue el resultado de la variedad de productores y de las disímiles disposiciones intelectuales que logró aglutinar ${ }^{27}$. De hecho, la lógica de tener dos agendas editoriales que se ampararon bajo un ejercicio de doble vía, uno vigilante, clásico, nativo apoyado en la naturaleza y otro vanguardista, extranjerizante, abierto y liberal $^{28}$ devela una hetereología estructural ${ }^{29}$ entre el campo editorial y el campo

25 Siguiendo la línea de Even-Zohar se habla en términos de productores y no de escritores o editores, porque su función no está confinada o limitada a un solo papel en la hipotética red litera que estoy trazando, sino que participan activamente en todo el conjunto de actividades del "sistema".

26 Aspecto que se veía reflejado en la sección ultima de la revista llamada al principio Pandemónium y después bautizada Notas y que presumiblemente eran autoría de Ramón Vinyes. Estás nunca iban firmadas.

${ }^{27}$ Ese "desbordamiento" en cuanto a materiales y productores -activos/suplementarios- que sufrió la Voces se ve reflejado en la universalidad de sus contenidos y en las misceláneas -notas, referencias, análisis- de las Notas de la revista. Críticas, lanzamientos, apologías, recuerdos, sensaciones, que develan un puente cultural que ejercicio el "sistema" literario manifestado desde la lección inaugural de Voces.

${ }^{28}$ Un lado agresivo que apeló constantemente a la imagen del famoso tren del Futurismo Italiano como a otros símbolos e imaginarios de las vanguardias europeas-, a ese gran pedazo de metal y remaches que rompe montañas, bosques, museos y bibliotecas a su paso para instaurar un nuevo 
de los productores. Esto propició, primero, una revista con una gran amplitud en temas, posturas, creencias y expresiones y, segundo, la inevitable necesidad de tener que implementar unos códigos que fueron bastante singulares y que estuviesen en constante cambio y alteración en sus tres años de existencia.

Visto así, la revista Voces se institucionalizó a partir de pequeñas revoluciones permanentes tanto en su campo editorial -tuvo tres editores en jefecomo en sus productores - diversas plumas con diferentes propuestas-. Este aspecto debe ser visto como un modo de transformación y adecuación cultural en busca de una supervivencia editorial frente a los campos tanto de producción cultural -otros periódicos y revistas que tenían marcos de operación restringida frente a un tipo de productos singulares- y los campos económicos y políticos que imponían sus agendas normalizadoras. Si su ley fue la independencia respecto a unas leyes de regulación editorial impuestas por unas demandas externas, su lógica de las prácticas tanto de circulación como apropiación de sus materiales escritos se basó en una inversión de los principios fundamentales del campo económico. Esta inversión buscó excluir, de su proyecto editorial, el afán de un beneficio monetario - a pesar de que una de sus fuentes ingresos más regulares eran las suscripciones- por la no co-relación entre la inversión de un capital simbólico/literario y el éxito comercial de la revista.

Ahora bien, a pesar de que Voces produjo sus propias geografías y sus leyes de funcionamiento, operó inevitablemente en los márgenes. A pesar de tener una existencia simbólicamente excluida y desacreditada en el ámbito barranquillero, logró posicionarse como una "rara avis" dentro del entramado cultural nacional. Cosa que ya se percibía desde la editorial inicial que presumiblemente escribió su fundador, Ramón Vinyes ${ }^{30}$. Esta separata que no aparece dentro el sumario general y que da inicio a la labor literaria de Voces reunió en sus líneas las directrices de no solo de quiénes lideraron la revista en sus primero años -Vinyes y Gómez de Castro- sino también para los otros dos años restantes -cuando la revista fue dirigida por Hipólito Pereyra-. "Prescindimos de la emoción real que surge de todo comienzo, para hacer el lector una confesión escueta de nuestros propósitos" (Voces 3). Lección inaugural, que no solo manifestaba la alegría del nacimiento de Voces, sino que, además, se exhibía, por primera vez, el carácter intimista y colectivo que iba a tener la revista a lo largo

orden de cosas literarias sobre los resquebrajados vestigios de la tradición vigente y una más amable que apelaba más al arado y a la pala de "Silva a la Agricultura de la zona tórrida" de Andrés Bello o la metáfora del Árbol de José Martí.

${ }^{29}$ Bourdieu usa un término en su estudio sobre el campo literario y sus reglas que es "homología estructural" (Bourdieu) para referirse a ciertos campos de producción cultural en el que tanto editores como escritores comulgan con los mismos códigos de expresión, políticas editoriales y tomas de posición. Por consiguiente, hago uso del antónimo "hetereología estructural" dado que Voces tuvo un código de expresión mutable dentro de sus tres años de existencia. Tanto sus productores como sus editores tenían códigos de expresión diversos mucho de ellos enfrentados, en plena contradicción.

${ }^{30}$ Jacques Girald (Gilard) y Ernesto Volkening en sus estudios realizados a Voces le asignan tanto la autoría de las Notas -o Pandemónium- como de las editoriales de la revista a Ramón Vinyes. 
de sus números no solo con sus suscriptores y lectores, sino también con sus escritores.

No viene a perturbar ni a entorpecer [...] solo deseamos conservar, durante el tiempo en que nos toque dirigir esta revista, que viene animada por honestos deseos, toda nuestra libertad de opinión y no limitada pureza en la labor de la selección [...]. No rehuimos de los grandes deberes patrióticos y personales que caen desde ahora sobre nosotros y nos resignamos a soportarla porque sabemos que nos rodearan generosamente cuantos espíritus se interesen por clarificar un poco más el horizonte de la acción artística [...]. (Voces 3 )

Además, se plantea el titánico ejercicio que iba a tener la revista al forjar una publicación decenal que se pregunta -artículo por artículo- por el ejercicio escrito de una nación, y anexo a ello, el de un continente en gestación. "Voces aisladas que se pierden en el espacio, sin estruendo pero conscientes de que oídos diversos están prontos a guardar su eco, a retenerlo sin indiferencia" (Voces 5) Una revista que "se presenta como un reflejo de reflejos, como ámbito propicio para voces aisladas [...]" (Voces 3). Preocupaciones de una naciente literatura americana -aludiendo constantemente a los discursos integracionistas de Pedro Henríquez Ureña y Alfonso Reyes-, y que apuntaban a la conformación de una literatura continental en donde su ejercicio fue esclarecer el horizonte de posibilidades escriturales del nuevo continente: "clarificar un poco más el horizonte de la acción artística, literaria y social de la América en general" (Voces 3).

Podríamos decir, que su código específico a pesar de estar en mutación constante apeló siempre a los lugares comunes de la vanguardia, a ciertos imaginarios que se inscribían en la ciudad como fue la representación en la revista de la fuerza y del renovado impulso de las jóvenes letras que aglutinó. Tradición, vejez y experiencia estrechamente ligada a la imagen del joven ${ }^{31}$ fue, en parte, el signo más característico de los productores de $\operatorname{Voces}^{32}$; lo que permitió que la revista asumiera una actitud desafiante con unas ganas insospechadas de escribir su propia historia en el continuum discursivo de la cultura caribeña y colombiana. Esa lucha que hace parte de la propia estructura de la revista, es decir, tanto por la oposición que tuvo como campo de producción cultural frente a las exigencias externas como, también, por las posiciones antagónicas que cifró en sus

${ }^{31}$ En la revista Voces fechada el 10 de Agosto de 1917 -la primera publicación de Voces- aparece ese signo de la juventud como el impulso espiritual de la revista "[...] El esfuerzo aunado de varías energías jóvenes, en las cuales hay un estremecimiento de inexperiencia, lanza al público este primer ejemplar [...]," (Notas 4)

${ }^{32}$ Ramón Vinyes -su fundador- y Blanco-quien participó activamente en la revista- eran los más grandes del grupo de productores de la revista, porque estaba compuesta en su gran mayoría por jóvenes promesas del periodismo, la crítica y la literatura tanto del Caribe como de otros territorios nacionales. 
decisiones editoriales entre literatura tradicional/literatura vanguardista y escritor consagrado/escritor joven.

Esto resultará valiosísimo porque al carecer de un capital específico dentro de la gama de los otros capitales existentes en Barranquilla decidieron jugársela el todo por el todo por una posición distinta y distintiva. Ese discurso diferenciado y diferenciador al que fue apelando obedeció, en primera medida, a la necesidad de hacerse de una identidad y poder, así, afirmarla en el concierto editorial local y nacional y, en segunda, porque al asumir esa diferencia de operación editorial $-\mathrm{y}$ que se le reconozca como tal, como una revista diferente- consiguió imponer nuevos modos de pensamiento y de expresión propios que fueron altamente rupturistas con los vigentes.

Por consiguiente, Voces apuntó a una lógica del desenmascaramiento para aquellos nuevos materiales, formas literarias y culturales presentes como un proceso de legitimación cultural, sorteándose para sí, una posición distintiva, pero sobre todo reconocible entre las superaciones, rupturas y prolongaciones culturales que ofreció la Barranquilla de su época. Discursos llevados con carácter y fuerza a una revista por jóvenes entusiastas que reunidos bajo la protección de dos grandes capitanes como fueron Ramón Vinyes y Enrique Restrepo llevaron a una edad madura, en plena guerra mundial, la mayor extravagancia de las letras colombianas. Pero ¿Quiénes fueron, entonces, los productores y agentes que asumieron ese espacio dentro de la estructura de la revista?

\section{Los Productores de la revista Voces}

La población de productores de la revista Voces estuvo compuesta por cinco editores que publicaron en los sesenta números como elementos activos de la revista $^{33}$ y un número indeterminado de elementos suplementarios que operaron de manera indirecta en los tres años de existencia ${ }^{34}$. Es necesario situar,

${ }^{33}$ La toma de decisión al igual que las políticas editoriales que se llevaron a cabo en la revista dentro de la práctica editorial de Voces no fue obra de un solo sujeto como se ha querido legitimizar en algunos estudios sobre la revista. Siempre se ha ubicado a Ramón Vinyes como la cabeza guía y único editor de la revista aspecto que sería muy difícil sostener no solo por la alta participación de otros productores activos en los sesenta números de la revista, sino, por los constantes exilios que padeció Vinyes en Barranquilla lo que produjo que la revista estuviera siempre a la deriva de su égida.

${ }^{34}$ En este trabajo se piensa la actividad "real" de los productores de Voces no solamente en el ejercicio de la producen textos, sino que se piensa como productores que participaron activamente en un conjunto actividades del total de la producción, fabricación y circulación de la revista. Hay dos tipos de productores, los primeros, son los elementos suplementarios que operaron de forma externa a la revista que son aquellos productores que no hicieron parte de manera directa de la estructura de Voces y de su campo editorial global y, que por ende, deberán ser entendidos como un número indefinido a causa de las múltiples participaciones de diversos escritores nacionales e internacionales que participaron en los tres años de existencia de la revista, a estos productores se les llamará suplementarios. Los segundos, son los elementos activos que son los productores que si hicieron parte tanto del grupo editorial -tomas de 
dentro de las prácticas internas llevadas a cabo por los productores activos, a la revista en su proceso de institucionalización bajo una particularidad que fue la de contar en su estructura con productores afectados por un nomadismo escritural y por las múltiples desubicaciones que se derivan como consecuencia de la expulsión tanto de sus comunidades de las que eran originarias como de los códigos culturales a los que respondían. Este elemento permitió, en parte, no solo a la definición de la revista y de su valor literario frente a sus similares, sino, que cada uno de los elementos activos de la revista pudiera disponer de un capital propio dentro del campo con pesos diferentes y diferenciados.

La revista contó con cinco grandes cabezas en sus tres años de vida editorial. Primero, el catalán exiliado en los inicios de la Guerra Civil en España, gran conocedor de la literatura universal y amante del teatro, Ramón Vinyes; seguido de quien fuera el primer director de la revista, J. Gómez de Castro, militante de las juventudes católicas y de afiliación conservadora y amante de las buenas lecturas; tercero, Hipólito Pereyra, gran comerciante, joven poeta y muy amigo de José Juan Tabalada con quien mantenía una extensa correspondencia, y quien fuera buen tiempo, el segundo director de la revista; cuarto, el primer filósofo del Caribe, traductor de Kant y de Nietzsche, Julio Enrique Blanco.; quinto y último, el padre de la crítica moderna en Colombia, Enrique Restrepo.

Este fue el grupo de editores que promocionó dentro de la revista el intercambio cultural a partir de la publicación de diversos productores nacionales y suplementarios. Escritores como Tomás Rueda Vargas, León de Greiff, Abel Farina, Vargas Vila, José Eustacio Rivera, Porfirio Barba Jacob, el "Tuerto" López, Gregorio Castañeda Aragón, José Félix Fuemayor, que publicaron en la revista, mostrando que la promoción de la literatura colombiana era un discurso dominante dentro de las políticas editoriales de Voces en el que se buscaba con su publicación el poder llevar a cabo varias antologías de la literatura colombiana, lo que sería redefinir los nuevas geografías de las letras colombianas ${ }^{35}$.

posiciones, políticas editoriales- como de los agentes internos a la revista, a estos se les llamará activos.

${ }^{35}$ La cara "colombiana" de la revista, que apuntaba a ciertas poéticas y proyectos políticos similares a los de de Andrés Bello, Rodó y Martí, no resulta algo sorprendente en Voces. La expresión de una literatura colombiana estrechamente vinculada a un imaginario de naturaleza aparece como la consecuencia de una revista que buscaba ser el centro de las realizaciones sociales y urbanas. Allí, se asomó con fuerza una Colombia no vista, en la que los campos, las florestas y las ceibas entusiasmaban la opacada retina de una sociedad barranquillera que fue urbanizada a velocidades insospechadas. No era lo mismo leer "Ritos" del gran bardo payanes, Guillermo Valencia, o celebrar los sonetos de José Eustacio Rivera, ambos publicados en Voces, en la ciudad de Barranquilla que haberlo leído en los periódicos y revistas de la ciudad capitalina, a sabiendas de la diferencia existente entre el desarrollo industrial y urbano que hubo entre una y otra ciudad. Ese llamativo acercamiento a una temática americanista y colombiana en Voces como parte de su estructura en tensión y del contacto directo del desarrollo tecnológico, de la expansión industrial y del fenómeno de urbanización que padeció la ciudad. No es gratuito ver publicado en el número 19 y 20 del veinte de abril de 1918 en el artículo "Pórtico" (Voces) fragmentos que apelan a una naturaleza caribeña presente en la escritura, lección que se repetirá el 20 de agosto de 1918 en una reseña sobre José Eustacio Rivera y un 
Voces se la jugó por un principio evidente que fue no definiendo fronteras ni controlando las entradas y salidas de quienes publicaban como de lo que era publicable decenalmente, aunque sí es necesario afirmar que cada material divulgado poseía dentro del campo editorial de la revista un peso y unas políticas editoriales diferentes como ocurrió con la agenda literaria en relación con otras disciplinas y saberes que convergían en la revista.

\begin{tabular}{|l|r|r|}
\hline Disciplinas: & Número de publicaciones & Porcentaje \\
\hline Literatura* & 233 & $85.34 \%$ \\
\hline Filosofía & 26 & $9.52 \%$ \\
\hline Ciencias -Positivismo- & 7 & $2.56 \%$ \\
\hline Teatro & 4 & $1.46 \%$ \\
\hline Música & 1 & $0.36 \%$ \\
\hline Artes plásticas & 2 & $0.73 \%$ \\
\hline
\end{tabular}

Ilustración 5. Datos del autor recolectados para este artículo.

En efecto, las relaciones de fuerzas internas en el seno de las prácticas y operaciones de los productores tanto activos como suplementarios estuvo siempre trastocado por la inminente irrupción, primero, de productores jóvenes así como de viejos escritores lo que permitió la importación y experimentación en novedades en materia de productos literarios y de técnicas de producción ${ }^{36}$ y, segundo, con la formación de un campo de fuerzas y contrapesos que codificaría el capital de cada material que fuese publicado en la revista ${ }^{37}$.

Este aspecto resulta de vital importancia porque el proceso de selección que se llevó a cabo en el interior del campo de productores en cuanto a lo publicable, se privilegió más la innovación desplazando su agenda editorial al servicio de autores "menos" comerciales y "menos" conocidos para el público colombiano que sobre aquellos que ya tenían un capital cultural/comercial establecido en el campo literario nacional. En sus páginas circularon algunos productores suplementarios que serían señalados posteriormente como las más grandes promesas de la literatura colombiana, así como también, se enfrentó

ensayo sobre la raza antioqueña de Libardo López, además, de la primera publicación de León de Greiff -cuando firmaba como Leo le Gris - en Voces con su "Balada Trivial de los 13 Panidas".

${ }^{36}$ Hipólito Pereyra, quien fuera la última cabeza líder de Voces en sus últimos números, modificó sus técnicas de producción poética debido a los materiales que llegaban a su revista. Comenzó a experimentar con la forma hasta el punto de publicar poemas en forma de caligramas.

${ }^{37}$ La revista Voces contó con 91 productores -entre activos y suplementarios- en sus sesenta números. El 35.16\% -que equivale al número de 32 de los productores-, eran jóvenes escritores carentes de un capital simbólico/cultural establecido dentro de los campos de producción cultural, el restante $65 \%$ eran escritores más avezados, productores viejos con un capital simbólico/cultural ya definido dentro de los campos de producción cultural tanto local como global. 
contra la mediocridad cultural que se vivía por esa época en Bogotá con polémicos cometarios que aparecían en las Notas y que eran escritos por Vinyes, Hipólito Pereyra y Enrique Restrepo ${ }^{38}$. Esas breves notas al final de la revista, como dice Germán Vargas, "procuraban remover la idílica paz del mundillo literario colombiano de esos años" (Vargas 125). Un ejercicio vanguardista que realzaba la revista en cada página y que la transformaron en una publicación contra-cultural tanto en la producción como por su difusión de materiales.

La revista operó siempre por medio de la ironía y la parodia, aspecto que estaría ubicado programáticamente dentro de las Notas finales. Dentro de ese espacio se pretendió generar, como política interna de la revista, una especie de insubordinación cultural en relación con otros campos de producción cultural. Una práctica que busco por todos los medios profanar la "seriedad" en la literatura y la lengua que había impuesto el centro cultural colombiano -Bogotá- a las periferias nacionales constituyéndose, asimismo, como un contra-discurso o como un contra-texto. "Nos reímos de pragmáticas, de instituciones, de prejuicios,

${ }^{38}$ Dentro del espacio dedicado en la revista Voces a las famosas "Notas" se hablaba todo acerca del mundo literario nacional e internacional. En la edición del 30 de octubre de 1917 -el director era Gómez de Castro- se burlan y critican la forma como percibe la literatura modernista y la nueva experimentación que está surgiendo en la poesía el Doctor Antonio Gómez Restrepo. "En esta época de anarquía literaria -dice Don. Antonio Gómez Restrepo- de descomposición del estilo y confusión de las ideas [...] El modernismo en literatura ha traído la imprecisión, la vaguedad (...) el uso de un vocabulario artificial y obscuro [...] de estados de alma indefinibles." (Voces 5). A este panorama desconsolador que plantea el crítico literario, la revista Voces responde al conservadurismo extremo del establishment colombiano -en cabeza de Restrepo- defendiendo las nuevas formas de literatura "Diríamos nosotros: en esta época de fuerte renovación; de inquietud; de estilos que luchan para expresar estados de alma inexpresivos; en esta época" "A nosotros nos pasma un crítico incomprensivo y con capilla abierta a un solo culto" (Voces 4). En la edición del 10 de Noviembre de 1917, con motivo del artículo publicado Núñez, poeta del crítico bogotano Baldomero Sanín Cano y la fuerte crítica efectuada por Voces -en cabeza de Vinyes- a la poética de Rafael Núñez se presentaron varios comentarios sueltos por parte del el establishment literario bogotano a la labor que estaba cumpliendo la revista Voces: "Voces, que ayer nos neutralizo a Núñez, nuestra gloria poética, nos neutraliza hoy a Gómez Restrepo, vuestro gran crítico [...] entre la necesidad espiritual de leer a Voces y el miedo de que nos arrebate una gloria nacional, nos sucede, a cada nueva entrega, lo mismo que cuando sentimos que la necesidad del remedio y le tememos la médico algún diagnostico fatal (Voces 4).respuesta que dio Voces "que un crítico y más aún un crítico de la reputación de Gómez Restrepo, no ha de tener una solo la medida ni un único punto de vista para considerar las cosas; que la crítica ha de ser amplia, comprensiva; que ha de reconocer la belleza en donde quiera que se encuentre.” (Voces 4). También criticaban la práctica de traducción de la literatura realizado en otros campos de producción cultural colombianos -se debe dejar claro, que gran parte del éxito fueron las traducciones que realizaron para su revista. Referencia a la traducción realizada por Caro a la Eneida de Virgilio y las críticas pertinentes de Voces "Aprovechamos la ocasión para dejar constancia de que la traducción de la Eneida de Virgilio hecha por el señor Caro, no nos satisface" (Voces 3) y hacen una comparación la de Fray Luis de León, dejando a la primera muy mal parada. La Critica nace a partir del espíritu católico de Caro quién no traduce lo que le parece indebido de las églogas y poemas de Virgilio. "Los autores o se traducen tal como escribieron o no se traducen" (Voces 4) La recepción negativa de Baudelaire por parte de los críticos bogotanos "Esos críticos miopes que ven a Baudelaire a un educador de almas o un aposto del mal" (Voces 3). 
de todos. Somos escépticos y pesimistas." (Voces 6) "revista un poco iconoclasta, que no es propiamente un pico de demoler, sino -sorpréndase lector intonso- una tribuna." (Voces 5). Aunque, se debe entender que esta apuesta por la crítica de situarse en los márgenes culturales para operar autónomamente, redujo el campo de recepción que tuvo la revista en aquella época. "Voces dice el burgués, es una promesa de indigestión, Voces dice la colectiva estupidez, es algo que no se entiende [...] Voces es algo exótico, dice la generalidad". Al fin de cuentas, un ejercicio periférico que implemento la ironía como una forma de arrebato y actitud desafiante:

Antioquia es la única que ha correspondido al llamamiento. De Bogotá casi no hemos recibido nada. ¡Ni canjes de periódicos! Trivializada galantería. [...] Voces - dice la curia-, perdóneseme la cobardía, que me embargaba y que me impide consignar el adjetivo calificador: No manden más la revista, dice. (Voces 4)

Esta faceta conflictiva, dentro de los marcos de producción, fue fundamental porque se volvió un índice manifiesto de uno de los primeros campos culturales vinculados a la promoción de la cultura escrita -por no decir el primero- que operó en el territorio nacional en oposición a los campos de producción cultural burgués-literarios predominantes en donde se buscaba más el valor y el éxito monetario a y el estatuto simbólico-comercial del productor acreditado -escritores consagrados- que la simple promoción literaria de jóvenes talentos -escritores no consagrados . Ninguna revista o periódico hasta entonces había afirmado de forma tan radical sus valores y pretensiones en el ámbito de la literatura colombiana, primero, dejando a un lado los lazos de dependencia financiera o comercial de los campos de producción cultural y, segundo, que, a través de la crítica y la parodia, trató de develar unos campos de producción cultural degradados y rezagados frente a las exigencias actuales.

A pesar de ser una pequeña empresa editorial ${ }^{39}$ con un número muy limitado de suscriptores como número de tirajes en comparación con sus similares, sus páginas rebosaron de productores como de materiales literarios sorprendentes. Su fuerza, es decir, el peso/valor que tuvo en el mercado cultural de la época puede asirse a través de la actitud que tuvo el campo editorial para obtener, por medio de sus productores y agentes, un estatus cultural diferencial cosa que se devela no solo por el prestigio y la antigüedad de algunos de sus productores, sino por la importancia que tenía dentro de las políticas editoriales la

${ }^{39}$ Si reconstruimos el campo editorial global de Voces encontramos un grado de codificación bastante débil por un lado en cuanto al capital económico y a los lazos financieros que manejaba, además, del poco éxito comercial que tuvo en la "arenosa" -su venta y consumo fue muy bajoen relación al rango que tenían sus similares en aquella época. Pero otro lado, un grado de codificación muy alto en cuanto al capital simbólico de quienes publicaron en ella: los productores activos y suplementarios. (Bourdieu) 
divulgación no solo de un tipo de literatura colombiana sino por la relevancia que se le dio a la literatura extrajera ${ }^{40}$.

Traducciones de primera mano se realizaban de los más diversos idiomas, dando como resultado una revista internacional, con un contenido que les ofrecía a los lectores de habla hispana materiales que jamás había leído en su lengua. Y esta originalidad produce un volcamiento de colaboraciones sobre la revista, especialmente del exterior. La traducción de diversos materiales en la revista debe ser visto como una modalidad de una nueva relación del público barranquillero con lo escrito. Estas traslaciones realizados por los productores y agentes activos del campo editorial de Voces permitieron no solo la ampliación de contenidos y tipos de literatura en la revista sino que generó a nivel urbano y social una mayor circulación para un tipo de textos que se presentaban como restrictivos para la mayoría de los círculos letrados barranquilleros por estar configurados en hablas que no eran de dominio público en la ciudad -en Voces se tradujo del italiano, del inglés, del alemán, del francés, del ruso, del japonés, etc.- Debe entenderse que las disposiciones culturales de la mayoría de los consumidores de literatura de la "arenosa" a pesar de convivir con múltiples experiencias extranjeras -aspecto que se devela en el fuerte campo publicitario que aparecía en los diarios y periódicos que circulaban en Barranquilla y que estaban escritos en diversas lenguas foráneas-, eran limitadas porque no hablaban en su gran mayoría más que el idioma oficial ${ }^{41}$. Por ello, la actividad de las traducciones que se realizaron en el campo editorial resultan ser ejes cardinales de su función difusora porque permitió que ciertos materiales literarios que no habían sido anteriormente transcritos al español y, por ende no habían sido nunca divulgados y consumidos en Colombia, al ser traducidos por Voces pudieron circular a un mayor número de consumidores $\mathrm{y}$, así, generar nuevos espacios sociales y culturales para su lectura ${ }^{42}$.

${ }^{40}$ Estos índices son propuestos por Bourdieu como parte integrante de lo que él llama como el capital simbólico del campo editorial: la localización del "sistema" frente a otros campos y fuerzas externas, la antigüedad tanto del productor como de los agentes que actúan en el "sistema", el prestigio del fondo editorial, los premios obtenidos, etc. (Bourdieu)

${ }^{41}$ La calidad cultural y social de los consumidores barranquilleros -o como los denomina Roger Chartier las propiedades de los lectores(Chartier). - muy a pesar de estar dotados de unas competencias específicas propias y diferencial es con otros públicos del territorio nacional gracias a la migración y al arribo de diversos capitales -humanos, culturales, discursivos- a la ciudad, el promedio de aquel público solo manejaba el español como única lengua.

${ }^{42}$ Nos queda añadir algo sobre la práctica de la traducción realizada en Voces y es reconocimiento de las dificultades inherentes a la misma, sino por la abundancia de textos en italiano, inglés, alemán, ruso, japonés que aparecieron en la revista Voces en sus setenta números y que para los cuales no existían traducciones en castellano para esa época. Además, que se trataban de traducciones muy especializadas a causa del lenguaje y la codificación de su lenguaje lo que presuponía ciertos conocimientos de historia del arte, de historia de la filosofía, historia de la ciencia, etc., de quienes tradujeron en Voces.

*Voces tradujo 54 textos -que equivale al $19.78 \%$ de las publicaciones totales de la revista Vocesen sus sesenta números lo que devela una gran tarea del "sistema" literario de Voces por publicar textos de otros hemisferios. 
Esa mentalidad de apertura, sin límites ni restricciones editoriales cuya singularidad determinó su ejercicio y práctica en el mercado editorial apareció como una solución particular a una ausencia evidente de normas y códigos específicos en la revista, lo que hizo que Voces fuera un caso único y exclusivo en el concierto hispanoamericano de las revistas culturales. Casos como los del catalán amigo de Ramón, C.A. Torres Pinzón, quien mantenía una estrecha relación con la revista y daba gratísimas pinceladas acerca de la cultura artística española o el Eugenio D’Ors, gran prosista y conocedor de poesía anglosajona, quién publicó regularmente bajo el seudónimo de Xenius. O que entre las páginas de la revista desfilaran nombres como el de Antonio Machado, Carlos Pellicer, Gabriela Mistral, Vicente Huidobro, José Juan Tablada y Enrique Diez Canedo. Espacio en donde también se leían por primera vez en español, poemas de Guillame Apollinaire, Paul Dermée, Luciano Folgore, Lino Cantaralli, Pierre Albert Birot, Pierre Reverdy, Max Jacoby otros escritores de los grupos postfuturistas y pre-surrealistas. Quizás, Voces fue el primer ejercicio consciente en el campo universal de las letras en Colombia, en donde un grupo definido de productores activos determinó la trayectoria que iba a tener la revista dentro del concierto de la cultura universal. Era común ver textos de André Gide, Aloysius Bertrand, Guillaume Apollinaire, R.B Cunninghame, Máximo Gorki, o advertir que la revista era una extensión cultural en donde se dieron a conocer las últimas teorías artísticas europeas encabezadas por el Futurismo Italiano, el Vibrismo, el Nunismo, el Cubismo, entre otros más.

Es en este sentido, que se puede comprender la inscripción de la lectura de "sistema" a Voces dado a las propias geografías y las propias divisiones que forjo (Casanova, La República mundial de las Letras ). Su campo concentró y acumuló recursos literarios y culturales en un plano que sobrepaso el plano estrictamente nacional y, más extensamente, el lingüístico al traducir una cuarta parte de estos, lo que estimuló a crear la revista más cosmopolita de Colombia y quizás del continente.

\section{Los consumidores de Voces, la formación de un público lector en la "arenosa".}

A partir de ciertas decisiones que tomó el campo editorial en cuanto a los materiales literarios y culturales publicados, la revista se desconectó en un punto de la realidad barranquillera en términos del consumo de la misma -la relación de la calidad del producto y el público al que llegaba- a causa de la gradual profesionalización y codificación que comenzó a demandar su estructura. Sus apuestas arriesgadas y novedosas la llevaron a aislarse de una mayor recepción para centrarse en un pequeño grupo de lectores que, resultaron ser la mayoría de las veces, los mismos productores activos y suplementarios de la revista. La cuestión, en este punto, no radica en la mera funcionalidad lector-recepción de la materialidad de Voces -aspecto que también es importante-, sino, en la "conciencia" cultural que estaba avizorándose en ella. 
La historia de la emergencia de nuevos espacios públicos en Barranquilla ligados a la aparición de campos de producción cultural vinculados a la circulación de materiales textuales como fue la revista Voces en una sociedad industrial, es signo de una nueva sociedad que iban surgiendo en Barranquilla, un sector que generó a su paso nuevos escenarios y cuyas brechas impusieron nuevos eslabones discursivos. El surgimiento de un nuevo mercado de competencias y habilidades, gracias al crecimiento industrial burgués, representó que en esos espacios públicos se diera una tecnificación de ciertas potencialidades del saber. Es evidente que este punto, acerca de la formación de un público lector es de especial relevancia en el proyecto editorial de Voces ya que una de sus finalidades era colocar la discursividad de la alta cultura en el espacio de lo público: en las calles, en las plazas, en las librerías, en el puerto. De tal manera, su despliegue visto como una fuerza discursiva emergente y con nuevas potencialidades del saber permitió que se generaran nuevas prácticas y maneras de utilizar esos nuevos recursos no materiales en esos espacios urbanos.

Por el otro lado, dentro de las atribuciones que trae el hablar de un tipo de consumidor en Barranquilla en cuanto al "verdadero" campo de recepción que haya podido tener la revista, a sabiendas de los problemas que sufrió a lo largo de sus tres años de vida - paras editoriales, no pago de los suscriptores, asfixia económica, críticas a su contenido-, muestran de manera particular la confusión, la indecisión y los conflictos que padecía Barranquilla por la reorganización del nuevo esquema urbano-burgués que se presentaba. Pero muy a pesar de ello, el activismo que logro proyectar el campo de producción de Voces en sus tres años de vida, de acuerdo a su funcionamiento, permitió a la larga la consolidación del esquema -cartografiado por Voces- de unas instituciones que operaron alrededor de ella.

Estos materiales literarios que hizo circular Voces en algunos circuitos culturales barranquilleros fueron consumidos bajo de dos formas: la primera de forma directa y la segunda de forma indirecta ${ }^{43}$. Estos tipos de consumo estuvieron mediados tanto por el espacio urbano y social de Barranquilla como por la calidad del público de la "arenosa" en esa época. Visto así, la construcción del sentido -y por extensión su consumo- de la revista por parte de los consumidores estuvo atado a dos niveles -o cruces como denomina Chartier (Chartier, De la historia del libro a la historia de la lectura 36)- , el primero, que alude a las propiedades de los lectores barranquilleros, los cuales estaban dotados de unas competencias y saberes que no estaban a la par de las exigencias de los materiales publicados por la revista, $\mathrm{y}$, segundo, por el dispositivo escritural como tal, es decir, la revista.

Hay que entender que el campo editorial de Voces se la jugó por una práctica de circulación y apropiación rupturista con lo tradicional sobre todo en el

${ }^{43}$ La teoría de la recepción tradicional supone teóricamente un tipo de lector, el cual se presenta altamente problemático pensar la práctica de apropiación solo en modos de lectura de los materiales textuales. Por ello, Even-Zohar (I. Even-Zohar) plantea dos tipos de consumo y de consumidores, uno, directo y, otro, indirecto. 
uso de su forma y de su impresión -la forma que publicaban sus escritos, pensar no más en el uso de las hojas impresas cuando publicaron los caligramas de Tabalada y Apollinarire no de forma vertical sino horizontal-, y la elección sociocultural que asumieron como revista. Colocada en el centro de la problemática, es necesario entender la forma de elección social en la que situó Voces, dada su naturaleza como campo de producción cultural vinculado a la difusión y promoción de materiales novedosos. El campo editorial de la revista no eligió como tal a un grupo social al que iría encaminado sus esfuerzos editoriales, ni tampoco eligió como tal un público lector. Su elección siempre fue más de conciencia, de querer hacer un ejercicio editorial desafiante, crítico, contracultural, más que uno de eficacia y eficiencia -entendiéndolo en el nivel volumétrico de sus publicaciones como el de sus consumidores-.

Voces, se limitó a un número reducido de lectores voluntarios y de consumidores directos a causa de las restricciones estéticas, culturales y educativas que sus mismos contenidos impusieron a lo largo de sus tres años. Pero claro está, que esto no quiera decir que no haya existido un consumo en Barranquilla de la revista, porque el consumo mayoritario en la ciudad fue indirecto. Las actividades aparentemente grupales que se realizaban en diversos circuitos culturales en la cuidad fue donde se originó el consumo indirecto de la misma. Consumo que se dio en la librería de Vinyes, en la casa de Restrepo, el club de Barranquilla, en los asientos del Camellón Abello, en la Plaza San Nicolas, etc. Una parte de la élite barranquillera consumió indirectamente una cantidad de fragmentos literarios y culturales que fueron promocionados en los contenidos de la revista y diversificados en los espacios de la "arenosa" - ver el cuadro A, B y C44.

\section{La Barranquilla de Voces: Por qué leer la revista Voces como un "sistema" literario.}

Después de lo expuesto, a partir de los criterios de evaluación y el proceso de autonomización del campo de producción se pueden develar varios elementos

\footnotetext{
44 El consumo indirecto de la revista Voces - de sus materiales publicados- fue siempre la constante por parte de los consumidores de Voces desde sus primeras ediciones, aspecto, que se hace completamente visible desde la edición número 10 con el primer problema económico que sufre el "sistema" literario de Voces. En esa para editorial se revelan dos cosas, primero, la insuficiencia económica y financiera que ya padecía el "sistema" a tan solo dos meses de haber salido su primera edición y, segundo, que el número de lectores -los suscriptores- estaba en rojo ya que no fue posible mantener ciertos privilegios en tanto en su edición como en su fabricación -recordemos que esa para obligó al "sistema" literario de Voces a cambiar la forma como fabricaba su revista-. Aunque, sí es cierto que las empresas editoriales duraban muy poco en Barranquilla -Rigoletto, El Estandarte, Guante Blanco, El Mercurio, etc.- si es preocupante reconocer que Voces nació con serias dificultades económicas a causa de los pocos suscriptores que tenía -lo que directamente condicionó su consumo directo-. Esa apuesta crítica, que parte de su política editorial de situarse en los márgenes culturales para operar autónomamente, redujo el campo de un consumo directo que tuvo la revista en aquella época.
} 
constitutivos para poder hablar de un "sistema" literario en Voces a nivel editorial: A) la generación de una expresión consciente acerca de la revista -reforzar y privilegiar ciertas lecturas sobre otras- que poseían tanto los editores como los productores de sí mismos como de la realidad sobre la que actuaban ${ }^{45}$; B) un estructura editorial autónoma que pretendía entender y representar la realidad (la suya propia: la de dominados o dominantes) desde su posición y; C) los efectos que la tomas de posiciones y elecciones estéticas -políticas editoriales- tuvieron en el desarrollo urbano-moderno de la ciudad en cuanto a la relación contradictoria de un mercado cultural inmaterial con uno material.

Cuando se habla de "sistema" literario en relación con Voces, es entenderlo como un campo de producción cultural abierto, dinámico y heterogéneo que contó con una multiplicidad de intersecciones, redes, o campos que trajeron una mayor complejidad en su estructuración -el comprender lo literario como algo que va más allá del mero texto ${ }^{46}$ para postular otras redes de significación cultural que la determinaron-. Con esto se pretende recalcar, primero, que el sistema" literario de Voces no contó con una uniformidad estructural como si eso fuese una condición sine qua non para poder hablar de "sistema". Es decir, que se puede dar cuenta de la función y funcionamiento sistémico de un artefacto literario como Voces develando su profunda heterogeneidad tanto en los materiales publicados, en su diversidad de productores y en sus políticas editoriales, así como en el campo en donde se movió. Y segundo, que una vez reconocida su "naturaleza" sistémica como algo histórico, modificable, cambiante, se nos presenta la revista como un objeto en relación con diversos agentes, instituciones, y repertorios.

Por consiguiente, al hacer a lectura de Voces como algo dinámico y heterogéneo con una estructura interna en la que gravitaron diversas redes de relación, se le esta asignando a la práctica literaria de la revista e Vinyes una aproximación mucho más funcional, es decir, que sus modos de operar en el espacio barranquillero estuvieron siempre fundamentados por una regulada organización y codificación. Esa heterogeneidad dentro de los márgenes de la funcionalidad nos muestra una fuerte codificación en términos de múltiples

${ }^{45}$ Bourdieu (Bourdieu, Una revolución) define esas realidades editoriales como unas propiedades distintivas que operarían bajo tres órdenes: el origen social de los productores y editores, el capital educativo con el que contaba cada uno y la trayectoria cultural y literaria.

46 Sostenemos, entonces, como hipótesis el uso del llamado "giro material", lo que nos permitirá establecer formas de abordaje novedosas y pertinentes para enriquecer el amplio campo de estudios relacionados con la revista Voces. Por ello, Consideramos importante realizar un planteo que concilie estos aportes. Desde el mismo campo disciplinario y ya más vinculado con la cuestión de Voces, el estudio sobre su circulación -qué ideas circulaban, qué géneros se imprimían, qué textos se seleccionaban, etc.- se relaciona con los estudios materialistas sobre el libro y la edición. El estudio de estos dos procesos - uno que deberá ser estudiado más como una institución que como un proceso- es que en ellos están cifrados todos los modos que contribuyen tanto a la fabricación, edición, traducción, recepción y consumo del "producto" final por parte del lector. Tanto uno como otro deben entenderse como dos series de operaciones definitivas que intervienen de manera directa sobre los textos. 
jerarquizaciones entre elementos y funciones como entre agentes y componentes inmersos dentro de la estructura de la revista. Con esto quiero decir, que la "integración" que hubo de estos campos autónomos dentro del "sistema" literario de Voces estuvo altamente mediado por un orden específico y singular, lo que, a fin de cuentas, constituiría el estado sincrónico - dinámico- del "sistema" literario, es decir, el grado de autonomía que pudo gozar la revista en Barranquilla ${ }^{47}$. El poder comprender la forma cómo se dinamizó los elementos dentro de Voces, nos ayuda a ampliar los márgenes discursivos acerca de la revista, es decir, que no solo re-definió lo que entendemos actualmente por literatura, sino que ese gesto, implicó un ir más allá y que estuvieron directa o indirectamente involucrados en el proceso de producción y fabricación de la revista. La idea es no seguir viendo a Voces como la mera unión de un conjunto de materiales literarios y culturales dentro de un corpus textual porque estos aspectos sólo son manifestaciones parciales de una actividad cultural mucho más global dentro su campo producción. Y es aquí, donde se acentúa con fuerza el hecho de entender a la industria misma de la revista más allá de su producto, viéndola como una actividad, como un "sistema" mucho más compleja que el agregado de unos cuantos materiales textuales, ya que estos solo son el resultado procesos y trayectorias. Por consiguiente, habrá que imaginar a Voces como una red hipotética, como un diseño "posible" de un campo de producción cultural que puso a circular en Barranquilla diversos materiales literarios, permitiendo, así, que se comprenda la revista como una "red de relaciones hipotetizadas entre una cierta cantidad de actividades llamadas "literarias", y -ver cómo- esas actividades operan alrededor- de esa red" (Even-Zohar 29).

\footnotetext{
47 Según Pierre Bourdieu existen dos principios de jerarquización en los campos de producción -o en los "sistemas" según Even-Zohar- uno externo y otro interno. En términos de esta investigación, el principio de jerarquización externa estará ligado a los campos de producción no cultural como lo son los campos económicos, financieros, portuarios, monetarios de aquella Barranquilla y que operaron como discurso dominantes y codificantes con un alto valor de cambio frente unas fuerzas internas no dominantes como las que actuaban en los campos de producción cultural en donde el valor era netamente simbólico como ocurrió en el "sistema" literario de Voces. Este aspecto resulta definitivo porque nos devela cómo se dieron las luchas $\mathrm{y}$, por ende, cuáles fueron los grados de jerarquización entre los diversos campos de poder y la revista, es decir, la relación/tensión que se originó entre el "sistema" literario de Voces como campo de producción cultural con otros campos y fuerzas externas que eran altamente dominantes y que eran de índole económico y político en la ciudad.
} 
CATEDRAL TOMADA: Revista de crítica literaria latinoamericana / Journal of Latin American Literary Criticism

La Barranquilla de Voces: ejercicios de una re-cartografía espacial.

¿Cómo circuló la revista Voces vista como una materialidad?

\section{Bibliografía}

Arciniega, G. «La Sala Samper .»El Tiempo 29 de Diciembre de 1994.

Bourdieu, Pierre. «Campos del poder, campo intelectual y habitus de clase.»

Bourdieu, Pierre. Intelectuales, política y poder . Editorial Eudeba , 2000. 23-42.

. Las Reglas del Arte. Editorial Anagrama, 1995.

. Las reglas del arte: Génesis y estructura del campo literario . Editorial Anagrama, 2006.

. «Una revolución conservadora en la edición .» Bourdieu, Pierre.

Intelectuales, política y poder . Editorial Eudeba , 2000. 223-270.

Cano, Fidel. El Espectador Diciembre de 1917.

Casanova, Pascale. La República mundial de las Letras . Barcelona : Editorial Anagrama, s.f.

Chamorro González, E. «Barranquilla 1920-1930: Expansión Urbana.» Villalón, Donoso. Historia de Barranquilla . Barranquilla : Ediciones Universidad del Norte , 2000. 183-221.

Chartier, Roger. «De la historia del libro a la historia de la lectura .» Chartier, Roger. Libros, lecturas y lectores en la Edad Moderna . Madrid: Editorial Alianza , 1994.

. El libro y sus poderes. Medellín : Editorial Universidad de Antioquia, 2009.

. El Mundo como representación. Historia Cultural: Entre prácticas y representación. Barcelona : Editorial Gedisa, 1992.

Even-Zohar. «Factores y dependencias en la cultura: Una revisión de la Teoría de los Polisistemas.» Santos, Iglesias. Teoría de los Polisistemas. Madrid: Arco/Libros, 1999. . Polisistemas de Cultura. Tel Aviv: Universidad de Tel Aviv , 2007.

Fondo Mixto de Promoción de la Cultura y las Artes . Imagen Tmeporal: Barranquilla Siglo XX. Barranquilla : Editorial Fondo Mixto de Promoción de la Cultura y las Artes, s.f.

Gilard, Jacques. Voces, un proyecto para Colombia. Barranquilla : Ediciones Universidad del Norte, s.f.

Goenaga, Miguel. Crónicas de la vieja Barranquilla . Barranquilla , 1953.

Illán Bacca, Ramón. Voces, 1917-1920. Barranquilla : Universidad del Norte, 2003.

Jakobson, Roman. «El metalenguaje como problema linguístico.» Jakobson, Roman. El marco del lenguaje . México D.F: Fondo de Cultura Económica, 1988. 81-91.

Loaiza Cano, G. «Voces de Vanguardia .» Revista Huellas (1997).

Madachi, Julio Nuñez. «Dimensión espacial y temporal originaria en la vida de Julio Enrique Blanco .» Huellas (1990): 5-18.

Medina, Álvaro. «Don Ramón, el maestro catalán de Cien años de soledad.» Pluma N. 31 (1975). 
Montoya Marquez, J. Barranquilla y sus trescientos años de existencia 16291929. Barranquilla : Litografía Barranquilla , 1929. . «Notas .» Voces 10 de Agosto de 1917.

Palacio, Julio H. La historia de mi vida. Barranquilla : Ediciones Universidad del Norte, 1992.

Rama, Ángel. La novela latinoamericana 1920-1980. Bogotá : Procultura , 1982. Vargas, Germán. Revisión de "Voces". Barranquilla: Ediciones Universidad del Norte, s.f. 